\title{
Chronic heat stress up-regulates leptin and adiponectin secretion and expression and improves leptin, adiponectin and insulin sensitivity in mice
}

\author{
Patrizia Morera, Loredana Basiricò, Kenji Hosoda ${ }^{1}$ and Umberto Bernabucci \\ Department of Agriculture, Forestry, Nature and Energy, University of Tuscia, via San Camillo De Lellis, SNC 01100 Viterbo, Italy \\ ${ }^{1}$ National Institute of Livestock and Grassland Sciences, National Agriculture and Food Research Organization, Tochigi, Japan \\ (Correspondence should be addressed to U Bernabucci; Email: bernab @ unitus.it)
}

\begin{abstract}
Heat stress (HS) induces adaptive responses that are responsible for alterations of carbohydrate and lipid metabolism. This study aimed to evaluate the effects of chronic heat treatment on the expression and secretion of leptin and adiponectin, important regulators of energy homeostasis, food intake and insulin action. C57BL/6 mice were subdivided into three groups (24 mice each). The first group was kept under control conditions $\left(\mathrm{C}: 22 \pm 2{ }^{\circ} \mathrm{C}\right)$. The second group was exposed to $\mathrm{HS}\left(35 \pm 1^{\circ} \mathrm{C}\right)$. The third group was kept under control conditions and was food restricted (FR). The HS group had higher rectal temperature than the $\mathrm{C}$ and $\mathrm{FR}$ groups and lower food intake than the $\mathrm{C}$ group. Hspa1 (Hspa1a) gene expression in adipose tissue, muscle and liver was higher under HS than FR and C. Heat treatment resulted in decreased blood glucose and non-esterified fatty acids; increased leptin, adiponectin and insulin secretion; and greater glucose disposal. Leptin, adiponectin, leptin and adiponectin receptors, insulin receptor substrate-1 and glucose transporter mRNAs were up-regulated in HS mice. This study provides evidence that HS improves leptin and adiponectin signalling in adipose tissue, muscle and liver. Heat stress was responsible for improving insulin sensitivity and glucose uptake in peripheral tissues, probably mediated by adipokines. Changes in the adipokine levels and sensitivity to them may be considered as an adaptive response to heat.
\end{abstract}

Journal of Molecular Endocrinology (2012) 48, 129-138

\section{Introduction}

Under a hot environment, the body's thermoregulatory system adjusts a variety of physiological mechanisms through a combination of dry heat exchange and evaporative heat loss to attain a balance between the heat produced within the body and the heat lost to the environment. Profound alterations at the cellular level also occur upon heat stress (HS).

These alterations encompass changes in gene expression and biochemical adaptive responses, characterised by the impairment of major cellular functions and reprogramming of cellular metabolism (Lindquist 1986).

In contrast to acute HS, the effects of chronic HS on gene expression and cellular metabolism have been studied only to a limited extent (Zhang et al. 2002, Bhusari et al. 2008). Acute and chronic HS pose two distinct challenges to animals. Acute HS (animals exposed to $40-42{ }^{\circ} \mathrm{C}$ for up to $24 \mathrm{~h}$ ) results in hyperthermia and can lead to death if subjects are exposed to it for an excessive length of time. In contrast, chronic HS $\left(33-35^{\circ} \mathrm{C}\right)$ can be tolerated for a longer period, and although it alters animal physiology (Gordon 1993, Horowitz 2002), it is non-lethal.
HS rodents exhibit increased basal insulin levels, greater insulin sensitivity and glucose uptake and lower plasma glucose (Torlinska et al. 1987, Gupte et al. 2009, 2011). These results agree with the findings in dairy cows that chronic HS leads to hypoglycaemia and increases basal insulin levels despite marked reductions in nutrient intake (Wheelock et al. 2010).

An increase in triglyceride content is observed in the liver of young rats (Ando et al. 1998) and dairy cows (Basiricò et al. 2011) exposed to a hot environment. In addition, decreased plasma cholesterol, phospholipid and non-esterified fatty acid (NEFA) contents are found in HS dairy cows (Sano et al. 1983, Ronchi et al. 1999). Ronchi et al. (1999) concluded that the alterations of carbohydrate and lipid metabolism in HS cattle are due to the high ambient temperature rather than indirect factors, such as the reduction of feed intake.

Two adipokines, leptin and adiponectin, are metabolically relevant in coordinating energy homeostasis (Ailhaud 2006). Leptin affects energy homeostasis by decreasing food intake and by up-regulating fatty acid oxidation and down-regulating lipogenesis in peripheral tissues (Rabe et al. 2008). Furthermore, leptin increases insulin sensitivity. Adiponectin regulates 
feeding behaviour through peripheral and central mechanisms and serves as a 'starvation' signal (Hoyda et al. 2011). Studies conducted on rodents demonstrate that adiponectin increases whole-body insulin sensitivity, decreases hepatic glucose production and increases fat oxidation in liver and muscle, leading to an overall decrease in fat deposition (Ailhaud 2006, Lafontan \& Viguerie 2006). In addition to its insulinsensitising effect, adiponectin may modify glucose metabolism by stimulating pancreatic insulin secretion (Rabe et al. 2008).

Few data are available on the interactions between HS and adipokine expression and secretion. To our knowledge, only such studies concern the effects of HS on leptin gene expression and secretion in birds (Al-Azraqi 2008, Dridi et al. 2008) and in lactating pigs (Renaudeau et al. 2003) and on leptin and adiponectin gene expression and secretion in mouse adipocytes (Bernabucci et al. 2009).

On the basis of our previous results (Bernabucci et al. 2009), we conducted a study to evaluate whether chronic HS rather than a reduction in voluntary food intake is associated with changes in the expression and secretion of leptin and adiponectin and in insulin sensitivity and glucose metabolism in peripheral tissues.

\section{Materials and methods}

\section{Animals and experimental design}

All animal procedures were reviewed by the Animal Care Ethics Committee of the University of Tuscia, Viterbo, Italy, approved by Italian Government Authorities, and were in accordance with European Guidelines. Seventytwo male C57BL/6 mice (Charles River Laboratories, Milan, Italy), 7 weeks old, were used. After an adaptation period of 14 days under control conditions $\left(22 \pm 2{ }^{\circ} \mathrm{C}\right.$; photoperiod: $12 \mathrm{~h}$ light:12 h darkness) and with ad libitum access to a standard chow diet (VRF1 diet, Charles River Laboratories), the animals were subdivided into three groups of 24 mice each. One group was kept under control conditions and fed ad libitum (C group; negative control). The second group was exposed to high ambient temperature (HS group; $35 \pm 1^{\circ} \mathrm{C}$; photoperiod: $12 \mathrm{~h}$ light:12 h darkness) for 5 days continuously and fed ad libitum. The third group was kept under control conditions and was food restricted (FR group; positive control) for 5 days. The level of food restriction corresponded to $80 \%$ of the dietary intake by control mice, which is a normal response of mice exposed to HS.

To avoid the influence of diurnal cycling, each experiment was started between 0800 and $0900 \mathrm{~h}$. Food intake, water consumption, body weight (BW) and rectal temperature (RT) were recorded daily. On 0 and 5 days, six animals from each group were used to perform a glucose tolerance test (GTT). At the beginning (day 0 ) and after 2 and 5 days of the experimental period, six animals from each group were killed via diethyl ether inhalation followed by cervical dislocation, and blood and tissue samples were collected immediately. Blood was collected into vials containing heparin and then centrifuged. The plasma was stored at $-20^{\circ} \mathrm{C}$ until analyses. Subcutaneous white adipose tissue (WAT), gastrocnemius skeletal muscle (M) and liver (L) samples were placed in RNA-Later solution (Ambion, Inc.) and frozen at $-80^{\circ} \mathrm{C}$ until total RNA isolation. Small intestine tissue samples were fixed in glutaraldehyde and paraformaldehyde for histological examination.

\section{HS treatment}

The HS protocol lasted for 5 days and was designed to induce moderate chronic stress, i.e. mice were continuously exposed to an ambient temperature of $35 \pm 1{ }^{\circ} \mathrm{C}$. Hyperthermia was induced via an infrared ceramic heat lamp ( $100 \mathrm{~W}$; Ceramicx Ireland Ltd., Cork, Ireland). There were four mice per cage (Metabolic cage 3700M022, Tecniplast, Varese, Italy), and the lamps were positioned above each cage at a distance of $10 \mathrm{~cm}$. The air temperature within the cage was checked every hour. The RT of the mice was measured every $2 \mathrm{~h}$ during the daytime (from 0800 to $1800 \mathrm{~h}$ ) using a thermistor probe (Temp JKT; Oakton Instruments, Vernon Hills, IL, USA).

The use of an infrared heat lamp to induce hyperthermia is safe: does not emit any type of light at the wavelengths to which murine retinal cells are sensitive and provides the opportunity to maintain the body temperature at any desired level for some time (Sharma 2007).

\section{Biochemical analysis}

Plasma indices of metabolic status were determined via an automatic analyser (IL-300 Plus, Instrumentation Laboratory, Lexington, MA, USA). Plasma glucose (kit from Instrumentation Laboratory) and NEFAs (NEFA-C kit; Wako Fine Chemical Industries, Dallas, TX, USA) were measured by enzymatic colorimetric methods. Plasma leptin, adiponectin and insulin were measured using commercial ELISA kits. The assays were conducted in 96-well microplates according to the manufacturer's instructions, with a Spectra-I microplate spectrophotometer (SLT Lab-Instruments GmbH, Grodig/Salzburg, Austria). Mouse leptin (sensitivity: $0.05 \mathrm{ng} / \mathrm{ml}$ ) and adiponectin (sensitivity: $0.5 \mathrm{ng} / \mathrm{ml}$ ) ELISA kits (Millipore, Billerica, MA, USA) were used to determine their blood concentrations. Insulin was measured using a Mouse Insulin ELISA Kit (Millipore), 
which had a sensitivity of $0 \cdot 2 \mathrm{ng} / \mathrm{ml}$. Inter- and intraassay coefficients of variability $(\mathrm{CV}, \%)$ were 3.85 and $1 \cdot 48$ for leptin, 5.97 and $5 \cdot 75$ for adiponectin and $9 \cdot 07$ and $2 \cdot 81$ for insulin respectively. All experiments were performed in duplicate.

\section{Glucose tolerance test}

GTTs were performed on six animals per group that had been fasted overnight for $16 \mathrm{~h}$. Animals were injected with $1.5 \mathrm{~g} / \mathrm{kg}$ BW of glucose into the peritoneal cavity. Glucose (OneTouch Ultra Easy, Lifescan, Milan, Italy) was measured in blood collected from the tail tip immediately before and at 30, 60, 90 and $120 \mathrm{~min}$ after the injection. After correcting for the levels at time zero (defined as baseline level), the glucose response to the GTT was calculated as the area under the curve (AUC) using the linear trapezoidal formula. The glucose AUC was reported from 0 to $120 \mathrm{~min}$.

\section{Real-time PCR}

Total RNA was isolated from the subcutaneous WAT, M and L using QIAzol Lysis Reagent (Qiagen) according to the manufacturer's instructions. One microgram of total RNA was reverse transcribed using an ImProm-II RT System (Promega) in a total volume of $20 \mu \mathrm{l}$ on a PCR Express thermal cycler (Hybaid, Ashford, UK). Controls without RT were performed to exclude the possibility of DNA contamination. Quantitative real-time PCR was performed following the manufacturer's recommendations using a LightCycler (Roche Applied Science) and a QuantiTect primer assay for mouse (Qiagen): leptin (QT00164360), adiponectin (QT01048047), leptin receptor (ObRb; QT00154133), adiponectin receptor 1 (AdipoR1; QT00154217), AdipoR2 (QT00165326), insulin receptor substrate 1 (Irs1; QT01540840), glucose transporter type 4 (Glut4 (Slc2a4); QT01538334), Glut2 (Slc2a2; QT00103537) and heat-shock protein-A1 (Hspa1 (Hspa1a): QT00254436). The gene expression levels were normalised using $\beta$-actin (Actb; QT01136772) mRNA as an internal control. PCR products were subjected to a melting curve analysis on the LightCycler and subsequently $2 \%$ agarose/Tris-borate-EDTA gel electrophoresis to confirm amplification specificity and amplicon size. To allow relative quantification after PCR, standard curves were constructed from the standard reactions for each target and Actb by plotting crossing point $(\mathrm{Cp})$ values, i.e. the cycle number at which the fluorescence signal exceeded background vs $\log$ cDNA dilution. The Cp reading for each of the unknown samples was then used to calculate the amount of either the target or the Actb relative to the standard using the Second Derivative Maximum
Method with the LightCycler Analysis Software 3.5 (Roche Applied Science). All reactions were performed in duplicate.

\section{Histological analysis}

At the end of the 5-day period, small intestine tissue samples were obtained for morphological assessment of epithelial damage. The tissue was fixed in $2.5 \%$ paraformaldehyde $+2.5 \%$ glutaraldehyde in cacodylate sucrose buffer $(0 \cdot 1 \mathrm{M}$ cacodylate, $0 \cdot 1 \mathrm{M}$ sucrose, $5 \mathrm{mM}$ $\mathrm{CaCl}_{2}$ and $5 \mathrm{mM} \mathrm{MgCl}_{2}, \mathrm{pH} 7 \cdot 2$ ) overnight at $4{ }^{\circ} \mathrm{C}$, rinsed in cacodylate buffer at $\mathrm{pH} 7 \cdot 2$ (three changes for $30 \mathrm{~min}$ at $4^{\circ} \mathrm{C}$ ) and then post-fixed in $1 \%$ osmium tetroxide in the same buffer for $1 \mathrm{~h}$ at $4^{\circ} \mathrm{C}$. Samples were dehydrated in an ascending series of alcohol solutions $(30-100 \%)$, infiltrated with a mixture of acetone:epon resin $\left(2: 1\right.$ for $1 \mathrm{~h}$ at $4{ }^{\circ} \mathrm{C}, 1: 1$ for $1 \mathrm{~h}$ at $4^{\circ} \mathrm{C}$ and $1: 2$ for $1 \mathrm{~h}$ at $4{ }^{\circ} \mathrm{C}$ ), embedded in epon resin overnight and polymerised at $60^{\circ} \mathrm{C}$ for $48 \mathrm{~h}$. Semi-thin sections $(1 \mu \mathrm{m})$ and ultrathin $(70 \mathrm{~nm})$ sections were cut using an Ultracut ultramicrotome (Reichert-Jung, Nussloch, Germany). Semi-thin sections stained with toluidine blue were observed using Axiophot optical microscope (Zeiss, Oberkochen, Germany). For transmission electron microscopy (TEM), ultrathin sections were collected on copper grids, stained with uranyl acetate and lead citrate and then observed using a Jeol 1200 EX II TEM (JEOL Datum Company, Tokyo, Japan).

\section{Statistical analysis}

Data were analysed using the MIXED procedure of the Statistica-7 Software package (Stat Soft, Inc., Tulsa, OK, USA) according to the following model:

$Y_{\mathrm{ijkl}}=\mu+\alpha_{\mathrm{i}}+\beta_{\mathrm{j}}+\gamma_{\mathrm{k}}+(\beta \gamma)_{\mathrm{jk}}+\varepsilon_{\mathrm{ijkl}}$

where, $Y_{\mathrm{ijk}}$, dependent variable; $\mu$, overall mean of the population; $\alpha_{\mathrm{i}}$, effect (random variable) of mice; $\beta_{\mathrm{j}}$, mean effect of day of sampling (days 0,2 and 5$) ; \gamma_{\mathrm{k}}$, mean effect of treatment (C, FR and HS); $(\beta \gamma)_{\mathrm{jk}}$, interaction of day of sampling $\times$ treatment; $\varepsilon_{\mathrm{ijk}}$, unexplained residual element assumed to be independent and normally distributed.

The repeated measures statement was used to analyse RT and GTT data. Each variable analysed was subjected to three covariance structures: compound symmetry, autoregressive order one and unstructured covariance. The covariance structure that had the largest Akaike's information criterion and Schwarz's Bayesian criterion was considered the most desirable. For all parameters tested, the best covariance structure was compound symmetry. Least-square means were separated with the predicted difference (PDIFF) procedure. Significance was declared at $P<0 \cdot 05$. 


\section{Results}

\section{Effects of HS on BW, food and water intake, RT and tissue Hspa1 gene expression}

At the beginning of the trial, the overall mean $( \pm$ s.D. $)$ BW for the C, HS and FR groups was 19.9 $\pm 2 \cdot 6,20 \cdot 7 \pm 2 \cdot 4$ and $20 \cdot 0 \pm 2 \cdot 2 \mathrm{~g}$ respectively. After 5 days of the experiment, the BW of $\mathrm{C}$ mice increased by $0.31 \mathrm{~g} /$ day, while in FR and HS mice, the BW decreased by 0.84 and $0 \cdot 14 \mathrm{~g} /$ day respectively. The overall food intake was higher in the control group $\left(0 \cdot 40 \pm 0 \cdot 05 \mathrm{~g} / \mathrm{g} \mathrm{BW}^{0 \cdot 75}\right)$ compared with the FR $\left(0 \cdot 25 \pm 0 \cdot 03 \mathrm{~g} / \mathrm{g} \mathrm{BW}^{0 \cdot 75}\right)$ and HS groups $\left(0 \cdot 29 \pm 0 \cdot 04 \mathrm{~g} / \mathrm{g} \mathrm{BW}^{0} \cdot 75\right)$. Water consumption was lower in the $\mathrm{C}$ and FR groups $(0.61 \pm 0.05 \mathrm{ml} / \mathrm{g}$ $\mathrm{BW}^{0.75}$ and $0.55 \pm 0.09 \mathrm{ml} / \mathrm{g} \mathrm{BW}^{0 \cdot 75}$ respectively) than in the HS group $\left(0 \cdot 70 \pm 0 \cdot 12 \mathrm{ml} / \mathrm{g} \mathrm{BW}^{0 \cdot 75}\right)$.

The temporal responses of RT and Hspal mRNA expression are shown in Fig. 1. RT was higher $(P=0 \cdot 0010)$ in HS mice compared with $\mathrm{C}$ and FR mice. No differences in RT were observed between $\mathrm{C}$ and FR mice during the 5-day experimental period (Fig. 1A). In HS mice, the RT peaked after 1 day of heat exposure and then started to decrease and remained slightly higher compared with $\mathrm{C}$ and FR until the end of the experiment.

\section{Plasma metabolite and hormone concentrations in HS mice}

Blood glucose was lower in the HS $(P=0 \cdot 0234)$ and the FR groups $(P=0 \cdot 0383)$ that the $\mathrm{C}$ group (Fig. 2A). The maximum decrease in plasma glucose was observed after 2 days in the HS group. In the FR mice, NEFA increased compared with $\mathrm{C}(P=0 \cdot 0384)$ and HS $(P=0 \cdot 0184)$. HS mice had the lowest NEFA $(P=0 \cdot 0456$; Fig. 2B).

The plasma concentrations of the adipokines and insulin in HS, FR and $\mathrm{C}$ mice are shown in Fig. 3. Compared with $\mathrm{C}$ and FR, plasma leptin (Fig. 3A) and adiponectin (Fig. 3B) were higher in the HS group after 2 days $(P=0 \cdot 0245)$ and 5 -day of HS $(P=0 \cdot 0313)$. At day 2 of $\mathrm{FR}$, adiponectin also increased $(P=0 \cdot 0413)$ when compared with $\mathrm{C}$. The concentration of insulin (Fig. 3C) increased markedly $(P=0 \cdot 0219)$ in HS mice, while FR induced a decrease when compared with $\mathrm{C}$, both on day $2(P=0 \cdot 0462)$ and day $5(P=0 \cdot 0471)$.

\section{Effects of HS on glucose tolerance}

As shown in Fig. 4A, at the beginning of the experiment (day 0 ), there were no detectable differences in glucose or behaviour during the GTT between the experimental (HS) and the control (FR and C) groups. On day 5 of the experimental period, glucose level, 30 min after the i.p. injection, was lower in the HS mice compared with the FR $(P=0 \cdot 0369)$ and $\mathrm{C}(P=0 \cdot 0401)$
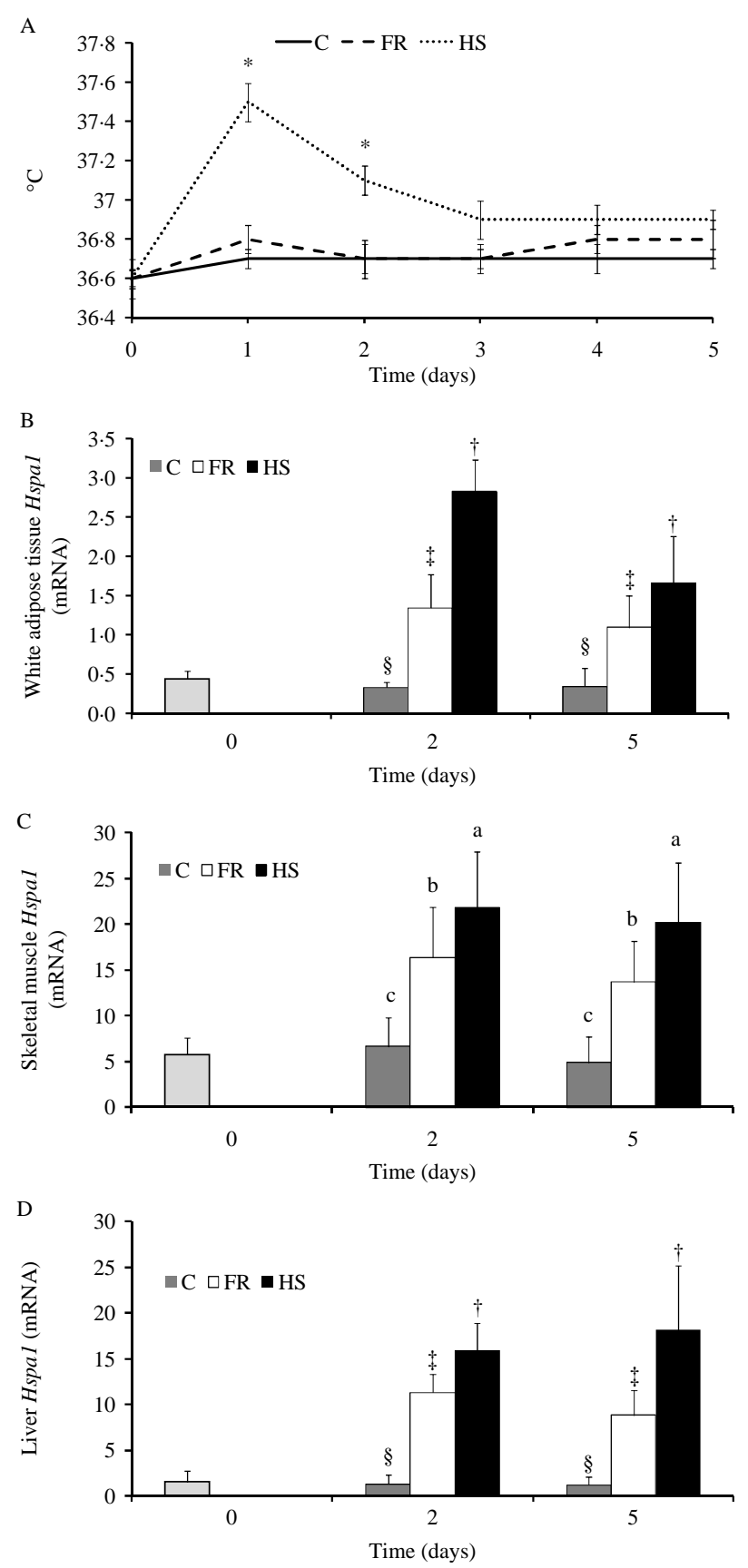

Figure 1 Kinetics of rectal temperature (A) and Hspa1 mRNA in subcutaneous white adipose tissue (B), skeletal muscle $(C)$ and liver (D) of control, food-restricted (FR) and heat-stressed (HS) C57BL/6 mice. The rectal temperature of the animals was measured using a thermistor probe (Temp JKT; Oakton Instruments, Vernon Hills, IL, USA) during the daytime. Each mRNA level was determined using quantitative real-time PCR as described in the Materials and methods section. Values are normalised to mouse $\beta$-actin mRNA expression. Time zero was considered as baseline. Data points indicate the mean \pm s.D., $n=6$. ${ }^{\star} P<0.05$ indicates higher values in HS mice compared with their counterparts ( $C$ and FR mice) within day, ${ }^{a, b, c} P<0.05$ and ${ }_{t, \neq, \S} P<0.01$ between treatments within day. 

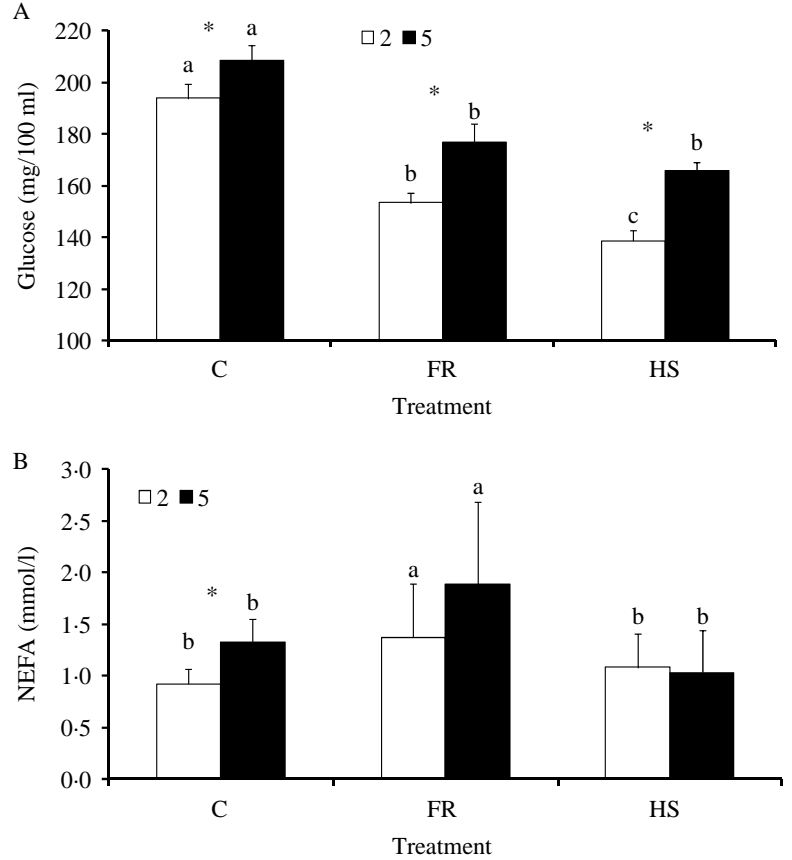

Figure 2 Plasma glucose (A) and non-esterified fatty acid (NEFA) concentrations (B) in control (C), food-restricted (FR) and heatstressed (HS) C57BL/6 mice at days 2 and 5 of the experimental period. Plasma indices of metabolic status were determined by an automatic analyser (IL-300 Plus; Instrumentation Laboratory, Lexington, MA, USA). Plasma glucose (kit from Instrumentation Laboratory) and NEFA (NEFA-C kit; Wako Fine Chemical Industries, Dallas, TX, USA) were measured by enzymatic colorimetric methods. Data points indicate the mean \pm s.D., $n=6$. ${ }^{\star} P<0.05$ between days within treatment; ${ }^{\mathrm{a}, \mathrm{b}, \mathrm{c}} P<0.05$ between treatments within day.

mice (Fig. 4B). FR mice had lower glucose $(P=0 \cdot 0354)$ than that observed in $\mathrm{C}$ but higher $(P=0 \cdot 0371)$ than that in HS mice. The decrease in the glucose AUC provided additional evidence that glucose clearance was affected by HS (Fig. 4C).

\section{mRNA expression of specific adipokines, their receptors, IRS1 and glucose transporters}

In Fig. 5, the specific mRNAs for leptin and adiponectin in the WAT are shown. Leptin mRNA expression in HS mice was up-regulated $(P=0 \cdot 0002)$ compared with $\mathrm{C}$ and FR mice (Fig. 5A). The differences in leptin mRNA expression remained significant until the end of the experimental period. Significant differences were observed in adiponectin mRNA expression (Fig. 5B) amongst the three groups. HS up-regulated $(P=0 \cdot 0226)$ adiponectin mRNA expression. Food restriction also up-regulated adiponectin compared with $\mathrm{C}$ both at day $2(P=0 \cdot 0294)$ and day $5(P=0 \cdot 0305)$.

Figure $6 \mathrm{~A} 1, \mathrm{~A} 2$ and $\mathrm{A} 3$ depict the changes in expression of $O b R b$ in WAT, $\mathrm{M}$ and $\mathrm{L}$ respectively.
In WAT and $\mathrm{M}$, the expression of $O b R b$ was up-regulated in HS $(P=0 \cdot 0172)$ and FR $(P=0 \cdot 0048)$ compared with $\mathrm{C}$, whereas in L, ObRb mRNA had the highest expression in HS mice after 2 days $(P=0 \cdot 0016)$ and 5 days of treatment $(P=0 \cdot 0002)$, and no differences were observed between $\mathrm{C}$ and FR mice.

The mRNA expression of adiponectin receptors (Adipor1 in WAT and $\mathrm{M}$ and Adipor2 in $\mathrm{L}$ ) is shown in Fig. 6B1, B2 and B3. In WAT and M, Adipor1 expression was up-regulated in HS $(P=0.0025)$ and FR $(P=0 \cdot 0018)$ mice compared with control. In L, Adipor 2 mRNA expression was the highest $(P=0 \cdot 0048)$ in HS
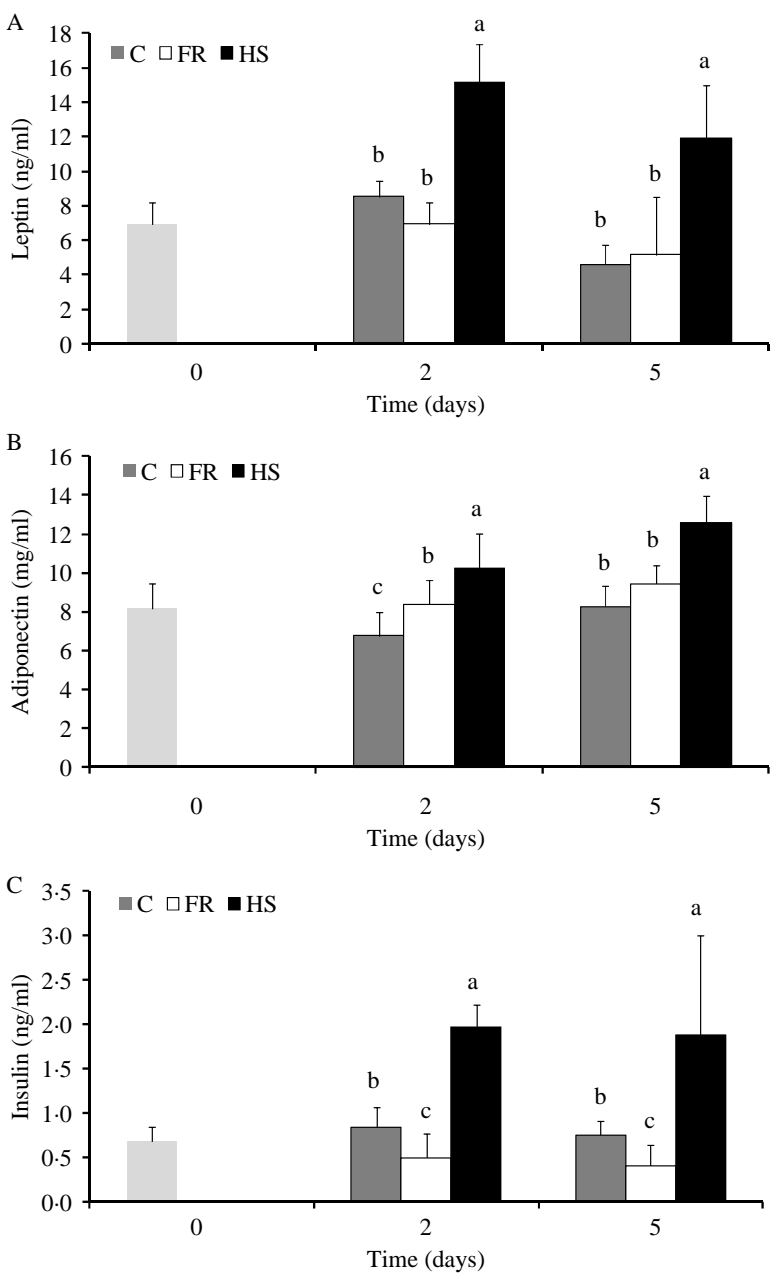

Figure 3 Leptin (A), adiponectin (B) and insulin secretion (C) in control (C), food-restricted (FR) and heat-stressed (HS) C57BL/6 mice during the experimental period. Plasma leptin, adiponectin and insulin were measured using commercial ELISA kits. The Mouse Leptin ELISA kit (Millipore) was used for leptin (sensitivity: $0.05 \mathrm{ng} / \mathrm{ml}$ ), and the Mouse Adiponectin ELISA kit (Millipore) was used for adiponectin (sensitivity: $0.5 \mathrm{ng} / \mathrm{ml}$ ). Insulin was measured using the Mouse Insulin ELISA kit (Millipore), and its sensitivity was $0.2 \mathrm{ng} / \mathrm{ml}$. Time zero was considered as baseline. Data points indicate the mean \pm s.D., $n=6$. ${ }^{\mathrm{a}, \mathrm{b}, \mathrm{c}} P<0.05$ between treatments within day. 

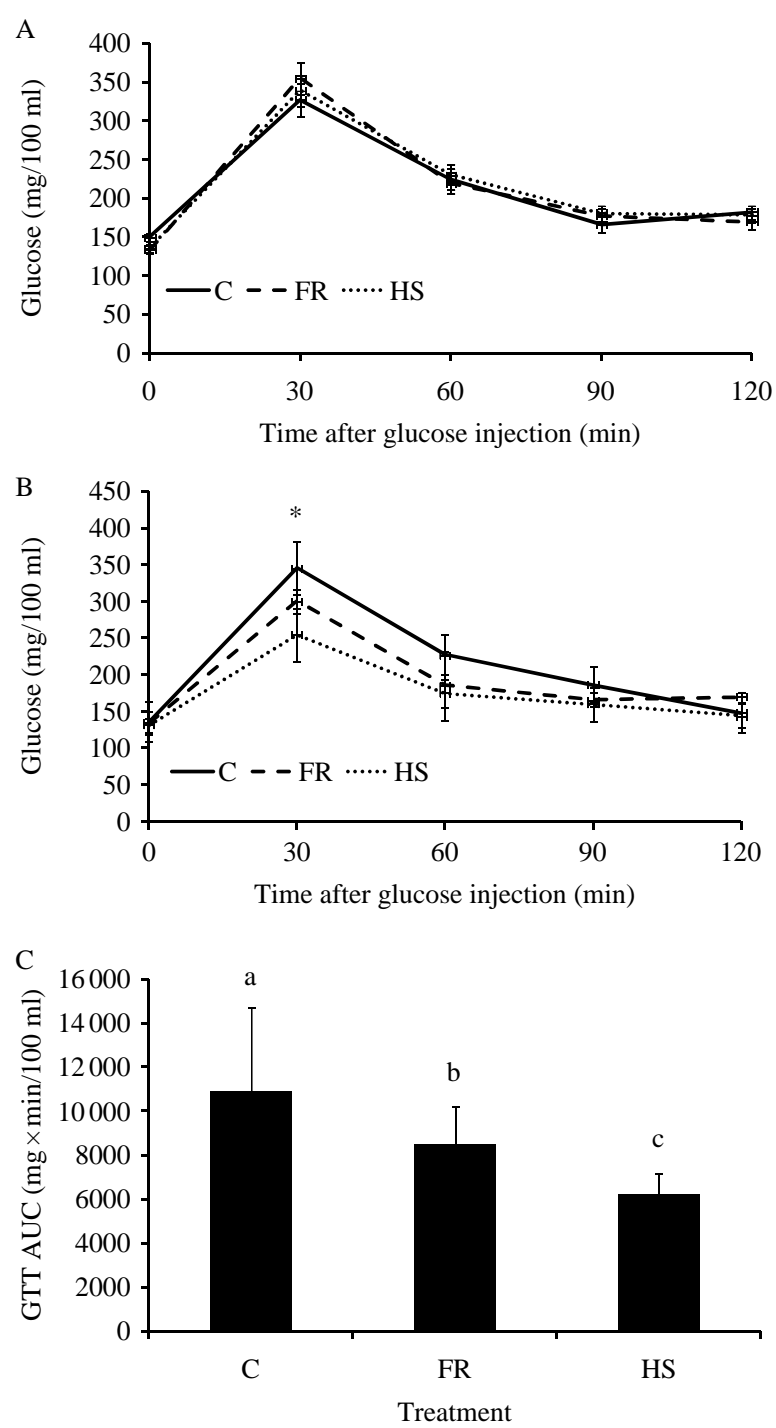

Figure 4 Intraperitoneal glucose tolerance test (GTT) curves obtained in control (C), food-restricted (FR) and heat-stressed (HS) C57BL/6 mice at day 0 (A) and day 5 of the experimental period (B); GTT is expressed as the glucose area under the curve (AUC) calculated at day $5(C)$. The animals ( $n=6$ mice per group) had been fasted for $16 \mathrm{~h}$ and were injected with $1.5 \mathrm{~g} / \mathrm{kg}$ body weight of glucose i.p. Blood glucose was measured 0, 30, 60, 90 and 120 min after injection using a glucometer (OneTouch Ultra Easy, Lifescan, Milano, Italy). Values are mean \pm s.D., $n=6$. ${ }^{\star} P<0.05$ between groups at 30 min after glucose injections a,b,c $P<0.05$ between treatments.

mice, but food restriction also induced an increase in Adipor 2 mRNA expression, both at 2 days $(P=0 \cdot 0023)$ and 5 days $(P=0 \cdot 0145)$, compared with $\mathrm{C}$.

The gene expression of Irs 1 in WAT, $\mathrm{M}$ and $\mathrm{L}$ is shown in Fig. 6C1, C2 and C3 respectively. In WAT and M, Irs 1 expression was up-regulated in $\mathrm{HS}(P=0 \cdot 0004)$ and FR $(P=0 \cdot 0034)$ mice compared with $\mathrm{C}$ (Fig. 6C1 and C2). In L, Irs $1 \mathrm{mRNA}$ was slightly $(P=0 \cdot 0437)$ up-regulated by food restriction and was markedly increased $(P=0 \cdot 0034)$ by HS (Fig. 6C3). These differences in Irs 1 mRNA expression amongst the three groups were significant until the end of the experimental period.

The mRNA expression of Glut4 and Glut2 in WAT and in L, respectively, was higher in HS mice than FR $(P=0 \cdot 0162)$ and $\mathrm{C}(P=0 \cdot 0030$; Fig. 6D1 and D3), whereas in M, food restriction also increased Glut4 mRNA until the end of the experimental period (Fig. 6D2).

\section{Intestinal barrier integrity in HS mice}

We performed electron microscopy on small intestine tissue samples to assess the effect of hyperthermia on epithelial morphology. Histological analysis by TEM revealed no significant changes in intestinal tissue in HS mice compared with mice kept under control conditions (Fig. 7). In particular, microvilli, mitochondria and tight junctions of HS mice were similar to those observed in the intestinal epithelium of C mice. Vacuolisation of epithelial cells was not visible in HS mice.
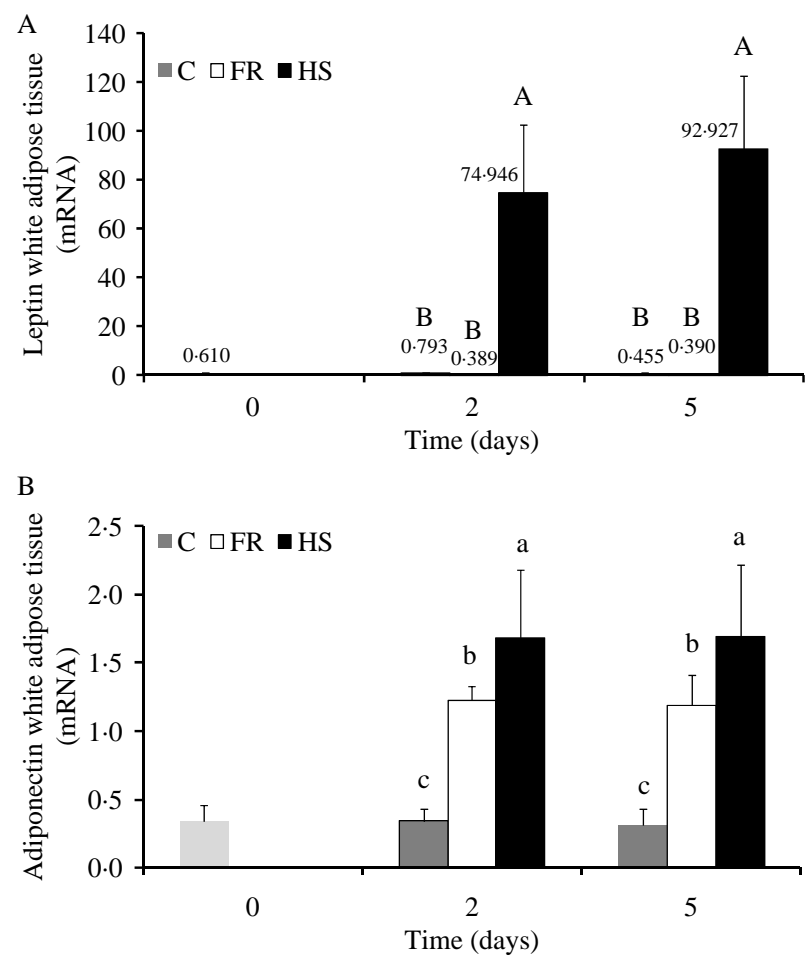

Figure 5 Leptin (A) and adiponectin mRNA expression (B) in subcutaneous white adipose tissue of C57BL/6 mice exposed to control (C), food restriction (FR) and heat stress (HS) conditions. Each mRNA level was determined using quantitative real-time PCR as described in the Materials and methods section. Values are normalised to mouse $\beta$-actin mRNA expression. Time zero was considered as baseline. Data points indicate the mean \pm s.D., $n=6$. ${ }^{\mathrm{a}, \mathrm{b}, \mathrm{C}} P<0.05$ and ${ }^{\mathrm{A}, \mathrm{B}} P<0.01$ between treatments within day. 


\section{Discussion}

As expected, chronic HS ( $35 \pm 1{ }^{\circ} \mathrm{C}$ for 5 days) resulted in decreased BW and food consumption and increased water intake and RT. The changes in those parameters, commonly used as indicators of the effects of HS on animal physiology, indicate that our mice were under conditions of moderate hyperthermia (Gordon 1993, Chung et al. 2008). The HS protocol used in this study was effective in inducing molecular responses in WAT, $M$ and $\mathrm{L}$, as shown by the increased expression of Hspa1. Interestingly, food restriction also induced an increase in Hspal gene expression, which seems to confirm that those changes were independent of hyperthermia. The exposure to HS is associated with an increase in the synthesis of HSPs, which protect cells against hyperthermia (Horowitz 2002). Moreover, Aly et al. (1994) have demonstrated an increase in HSP expression in tissues of animals maintained under caloric restriction. Low caloric intake is considered a mildly stressful condition that induces a survival response and therefore increases the organism's defences (Sinclair 2005).

The reduction of food intake commonly observed in HS animals is a response aimed to reduce digestion and metabolic heat production (Johnson 1987, Speakman \& Król 2010). Considering that HS and food restriction generate stress conditions that induce a derangement of metabolic and behavioural homeostasis in animals, it was an important aim of our study to discriminate cellular/metabolic effects due to HS-induced reductions in food intake from those associated with food deprivation alone.

The up-regulation of leptin and adiponectin gene expression and secretion observed in this study agrees
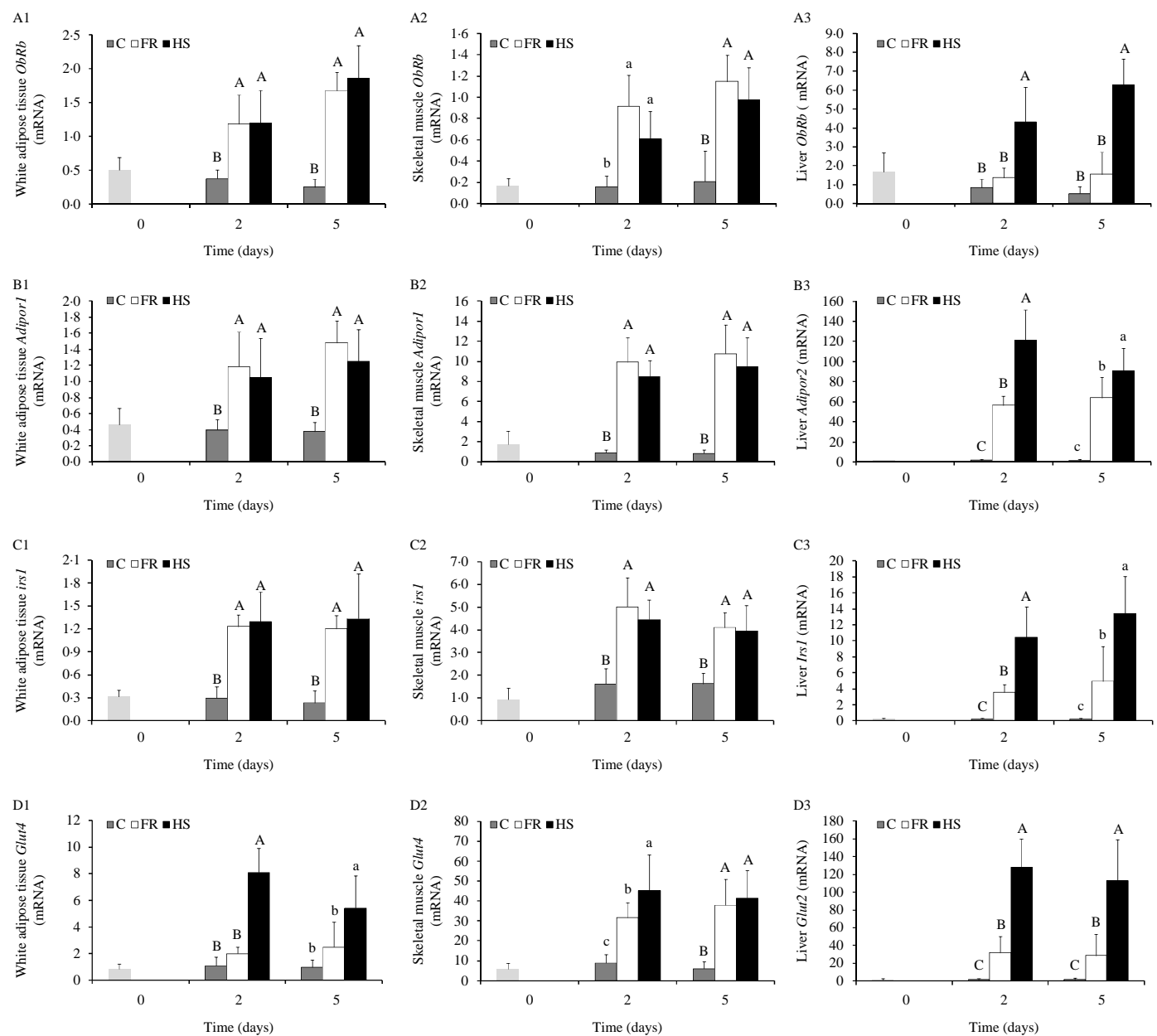

Figure 6 mRNA expression of leptin receptor $(O b R b)(A)$, adiponectin receptors (Adipor1 and Adipor2) (B), insulin receptor substrate 1 (Irs1) (C) and glucose transporters (Glut2 and Glut4) (D) in subcutaneous white adipose tissue (1), skeletal muscle (2) and liver (3) of C57BL/6 mice exposed to control (C), food restriction (FR) and heat stress (HS) conditions. Each mRNA level was determined using quantitative real-time PCR as described in the Materials and methods section. Values are normalised to mouse $\beta$-actin mRNA expression. Time zero was considered as baseline. Data points indicate the mean \pm S.D., $n=6$. ${ }^{\mathrm{a}, \mathrm{b}, \mathrm{c}} P<0.05$ and ${ }^{\mathrm{A}, \mathrm{B}, \mathrm{C}} P<0.01$ between treatments within day. 

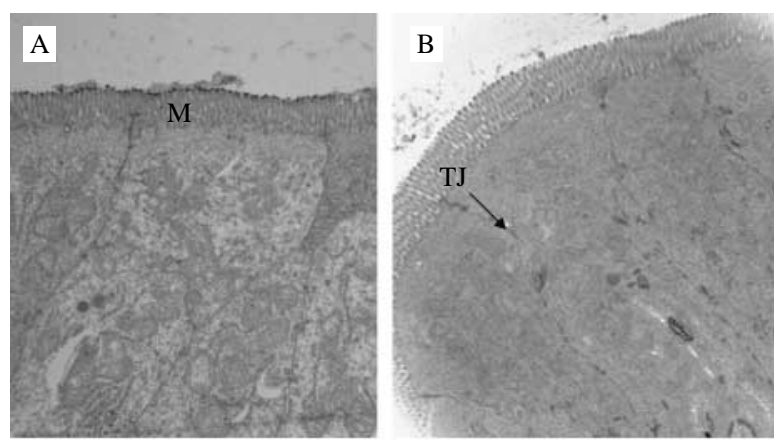

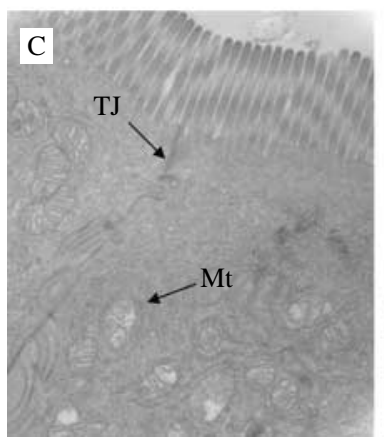

C mice

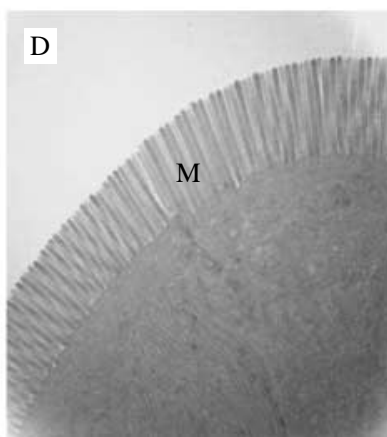

HS mice
Figure 7 Transmission electron micrographs of small intestine epithelial cells from mice exposed to control (C) or heat stress (HS) conditions. Control mice were maintained at an ambient temperature of $22 \pm 2{ }^{\circ} \mathrm{C}$ for 5 days. HS mice were continuously maintained at an ambient temperature of $35 \pm 1{ }^{\circ} \mathrm{C}$ for 5 days. Note: no damage to microvilli (M), tight junctions of cell membranes $(\mathrm{TJ})$ or mitochondria (Mt) and no vacuolisation are present in HS mice. Microscopic magnification: (A and $B$ ), $10000 \times$; (C and D), $25000 \times$.

with our previous in vitrofindings (Bernabucci et al. 2009), confirming a role of HS in modulating leptin and adiponectin gene and protein expression. In HS and FR mice, the circulating leptin and adiponectin levels paralleled the respective responses in WAT leptin and adiponectin gene expression. Our findings regarding leptin and adiponectin in FR mice agree with previous human and mouse studies, indicating that caloric restriction induces a reduction of leptin and an increase in adiponectin expression (del Mar Romero et al. 2009, Lee et al. 2010). The same result was not observed in HS mice, in which heat treatment significantly increased both leptin and adiponectin secretion and expression. Therefore, these data suggest that HS alters leptin and adiponectin levels independently of food restriction.

Hyperthermia increases intestinal permeability in a variety of mammalian species (Barthe et al. 1998, Lambert et al. 2002), facilitating the passive nonmediated diffusion of both small and large molecules (e.g. endotoxins) from the gastrointestinal lumen to the blood. Endotoxins entering the blood stream may induce the development of inflammation by stimulating the secretion and release of a variety of pro-inflammatory factors (Lambert et al. 2002). Landman et al. (2003) reported that endotoxins stimulate the release of leptin into peripheral blood in rodents, humans and non-human primates. Lower levels of adiponectin are associated with low-grade chronic inflammation and increases in pro-inflammatory factors (Fantuzzi 2008). Under HS conditions in our study, the intestine maintained a normal epithelial morphology. This response might exclude the possibility of a heat-stressed inflammatory state mediated by altered intestinal permeability. Consequently, the observed changes in leptin and adiponectin gene expression and secretion in HS mice were likely an effect of HS on mechanisms that modulate the secretory function of WAT.

The molecular mechanisms by which HS regulates the expression and secretion of adipokines remain largely unknown. Park et al. (2005) suggested that changes in the fluidity of membrane lipids, induced by high temperature, may cause signal transduction that would induce a cellular heat-shock response, e.g. greater HSP expression, that could directly stimulate adipokine expression.

Chronic heat treatment, by up-regulating $O b R b$ and Adipor1 and Adipor2 gene expression, seemed to elicit a significant increase in leptin and adiponectin sensitivity in WAT, M and L. Previous studies on HS animal models reported that despite marked reductions in nutrient intake, HS animals did not show an increase in plasma NEFA, had lower plasma glucose, increased basal insulin levels and stimulated glucose uptake (Torlinska et al. 1987, Ritchie et al. 1994, Ronchi et al. 1999, Gupte et al. 2009, Wheelock et al. 2010). All those responses and the up-regulation of $O b R b$ and adiponectin receptors in this study suggest that adiponectin and leptin might play roles in modulating the post-absorptive energetic metabolism of HS subjects. Chronic HS and caloric restriction led to distinct patterns of expression of the leptin and adiponectin receptor genes in $\mathrm{L}$, while these genes were similarly affected in WAT and M. The different responses of $\mathrm{L}$, probably because of its major vulnerability and sensitivity to HS, emphasise the key role that $\mathrm{L}$ plays in orchestrating the main pathways of energy metabolism under HS conditions.

Adiponectin and leptin are important physiological insulin sensitisers (Rabe et al. 2008). These adipokines act locally or distally to modify insulin sensitivity in insulin target organs such as WAT, $\mathrm{M}$ and L. The suggested mechanism whereby adiponectin increases insulin sensitivity involves the suppression of hepatic glucose production and an increase in fatty acid oxidation by $\mathrm{M}$ and $\mathrm{L}$, thereby reducing the levels of plasma NEFA (Berg et al. 2001). Adiponectin stimulates glucose uptake in adipocytes and $\mathrm{M}$ by activating 5'-AMP-activated protein kinase (Kadowaki et al. 2006, Klimcakova et al. 2006) and stimulates insulin secretion 
by the pancreas. Leptin also activates $5^{\prime}$-AMP-activated protein kinase and enhances fatty acid oxidation in $\mathrm{M}$ and L (Klimcakova et al. 2006). It also modulates hepatic gluconeogenesis and pancreatic $\beta$-cell function (Rabe et al. 2008). Data from the current study suggest that similar mechanisms as those found previously may be activated by HS. Therefore, the results from this study provide initial evidence of the molecular mechanisms through which HS induces insulin sensitivity in peripheral tissues. In particular, HS seems to have a greater impact on insulin sensitivity in the $\mathrm{L}$ than in the WAT and M.

The present results lead to questions as to why chronic HS affected the gene expression and secretion of leptin and adiponectin, seemed to enhance leptin and adiponectin sensitivity in peripheral tissues and improved insulin sensitivity. On the basis of previous data, we suggest that these changes can be considered an acclimatisation of homeothermic animals to HS, i.e. a way to increase avenues of heat loss and reduce heat production in an attempt to remain euthermic. Those responses include decreased food intake, increased water intake and increased respiration and perspiration rates, all leading to increased maintenance costs.

The immediate response to heat load and the heatinduced changes in homeorhetic modifiers may alter post-absorptive energy, lipid and glucose metabolism. How these metabolic changes are initiated and regulated is not well known. The up-regulation of leptin and adiponectin expression in adipose cells exposed to heat shock might be one of the mechanisms involved in acclimation to a hot environment, i.e. a central action that leads to decreased food intake and limits body hyperthermia (Nogueiras et al. 2004, Hoyda et al. 2011). On the other hand, the up-regulation of adiponectin may be responsible for the increased pancreatic insulin secretion observed in HS animals. These adipokines might allow cells to better resist the damaging effects of HS. Indeed, our data show that HS animals experience a variety of post-absorptive metabolic changes that are not typical of animals under a lowered nutritional plane. With regard to lipid and carbohydrate metabolism, this is primarily characterised by the lack of WAT lipid mobilisation, increased basal and stimulated insulin release and increased glucose disposal.

An increase in glucose pool entry coupled with a decrease in blood glucose may suggest a higher rate of glucose leaving the circulating blood pool; thus, glucose appears to become a favoured fuel for HS animals. That suggestion is supported by the increase in respiratory quotient observed in hyperthermic humans (Febbraio 2001). The apparent switch in metabolism and the increase in insulin sensitivity are probably a mechanism by which animals decrease metabolic heat production. Despite having a much greater energy content, as a result of differences in the efficiencies of capturing ATP, oxidising fatty acids generate more metabolic heat compared with glucose (O'Brien et al. 2010). Therefore, during HS preventing or blocking adipose mobilisation or breakdown and increasing glucose 'burning' is presumably a strategy to minimise metabolic heat production (Wheelock et al. 2010).

In summary, the current study provides some of the first evidence regarding the likely specific effects of chronic HS on leptin and adiponectin gene expression and secretion by WAT. HS appeared to improve leptin and adiponectin signalling in WAT, M and L. Changes in the levels and sensitivity of these adipokines may be considered an adaptive response to HS conditions. Moreover, our findings suggest that chronic heat treatment independent of reduced food intake was responsible for improving insulin sensitivity and glucose uptake in peripheral tissues, probably mediated by the adipokines. Collectively, these data indicate that moderate chronic heat treatment could be a potential therapeutic treatment for disorders associated with insulin resistance.

\section{Declaration of interest}

The authors declare that there is no conflict of interest that could be perceived as prejudicing the impartiality of the research reported.

\section{Funding}

This work was supported by funding from Italian Government Ministry of University and Research (PRIN-2007).

\section{Acknowledgements}

The authors thank F Gentili for animal handling.

\section{References}

Ailhaud G 2006 Adipose tissue as a secretory organ: from adipogenesis to the metabolic syndrome. Comptes Rendus Biologies 329 570-577. (doi:10.1016/j.crvi.2005.12.012)

Al-Azraqi AA 2008 Pattern of leptin secretion and oxidative markers in heat-stressed pigeons. International Journal of Poultry Science 7 1174-1176. (doi:10.3923/ijps.2008.1174.1176)

Aly KB, Pipkin JL, Hinson WG, Feuers RJ, Duffy PH, Lyn-Cook L \& Hart RW 1994 Chronic caloric restriction induces stress proteins in the hypothalamus of rats. Mechanisms of Ageing and Development 76 11-23. (doi:10.1016/0047-6374(94)90003-5)

Ando M, Kobayashi N, Kawahara I, Asanuma S \& Liang CK 1998 Impacts of heat stress on hyperthermic disorders and heat stroke. Global Environmental Resources 2 111-120.

Barthe L, Woodley JF, Kenworthy S \& Houin G 1998 An improved everted gut sac as a simple and accurate technique to measure paracellular transport across the small intestine. European Journal of Drug Metabolism and Pharmacokinetics 23 313-323. (doi:10.1007/ BF03189357) 
Basiricò L, Morera P, Lacetera N, Ronchi B, Nardone A \& Bernabucci U 2011 Down-regulation of hepatic $\mathrm{ApoB}_{100}$ expression during hot season in transition dairy cows. Livestock Science 137 49-57. (doi:10.1016/j.livsci.2010.09.027)

Berg AH, Combs TP, Du X, Brownlee M \& Scherer PE 2001 The adipocyte-secreted protein Acrp30 enhances hepatic insulin action. Nature Medicine 7 947-953. (doi:10.1038/90992)

Bernabucci U, Basiricò L, Morera P, Lacetera N, Ronchi B \& Nardone A 2009 Heat shock modulates adipokines expression in 3T3-L1 adipocytes. Journal of Molecular Endocrinology 42 139-147. (doi:10.1677/JME-08-0068)

Bhusari S, Hearneb LB, Spiers DE, Lamberson WR \& Antoniou E 2008 Transcriptional profiling of mouse liver in response to chronic heat stress. Journal of Thermal Biology 33 157-167. (doi:10.1016/j.jtherbio. 2008.01.001)

Chung J, Nguyen AK, Henstridge DC, Holmes AG, Chan MH, Mesa JL, Lancaster GI, Southgate RJ, Bruce CR, Duffy SJ et al. 2008 HSP72 protects against obesity-induced insulin resistance. PNAS $\mathbf{1 0 5}$ 1739-1744. (doi:10.1073/pnas.0705799105)

Dridi S, Temim S, Derouet M, Tesseraud S \& Taouis M 2008 Acute cold- and chronic heat-exposure upregulate hepatic leptin and muscle uncoupling protein (UCP) gene expression in broiler chickens. Journal of Experimental Zoology 309A 381-388. (doi:10.1002/ jez.461)

Fantuzzi G 2008 Adiponectin and inflammation: consensus and controversy. Journal of Allergy and Clinical Immunology 121 326-330. (doi:10.1016/j.jaci.2007.10.018)

Febbraio MA 2001 Alterations in energy metabolism during exercise and heat stress. Sports Medicine 31 47-59. (doi:10.2165/00007256200131010-00004)

Gordon CJ 1993 Temperature acclimation. Temperature Regulation in Laboratory Rodents. pp 163-180. New York: Cambridge University Press.

Gupte AA, Bomhoff GH, Swerdlow RH \& Geiger PC 2009 Heat treatment improves glucose tolerance and prevents skeletal muscle insulin resistance in rats fed a high-fat diet. Diabetes $\mathbf{5 8} 567-578$. (doi:10.2337/db08-1070)

Gupte AA, Bomhoff GL, Touchberry CD \& Geiger PC 2011 Acute heat treatment improves insulin-stimulated glucose uptake in aged skeletal muscle. Journal of Applied Physiology 110 451-457. (doi:10.1152/japplphysiol.00849.2010)

Horowitz M 2002 From molecular and cellular to integrative heat defense during exposure to chronic heat. Comparative Biochemistry and Physiology. Part A, Physiology 131 475-483. (doi:10.1016/S10956433(01)00500-1)

Hoyda TD, Samson WK \& Ferguson AV 2011 Central nervous system roles for adiponectin in neuroendocrine and automic function. In Adipokines, pp 167-184. Eds VR Preedy \& RJ Hunter. Boca Raton, FL, USA: Science Publishers, CRC Press.

Johnson HD 1987 Bioclimate and Livestaock. In Bioclimatology and the adaptation of livestock, pp 3-16. Ed HD Johnson. Amsterdam, The Netherlands: Elsevier Science Publisher.

Kadowaki T, Yamauki T, Kubota N, Hara K, Ueki K \& Tobe K 2006 Adiponectin and adiponectin receptors in insulin resistance, diabetes, and the metabolic syndrome. Journal of Clinical Investigation 116 1784-1792. (doi:10.1172/JCI29126)

Klimcakova E, Polak J, Moro C, Hejnova J, Majercik M, Viguerie N, Berlan M, Langin D \& Stich V 2006 Dynamic strength training improves insulin sensitivity without altering plasma levels and gene expression of adipokines in subcutaneous adipose tissue in obese men. Journal of Clinical Endocrinology and Metabolism 91 5107-5112. (doi:10.1210/jc.2006-0382)

Lafontan M \& Viguerie N 2006 Role of adipokines in the control of energy metabolism: focus on adiponectin. Current Opinion in Pharmacology 6 1-6. (doi:10.1016/j.coph.2006.08.002)

Lambert GP, Gisolfi CV, Berg DJ, Moseley PL, Oberley LW \& Kregel KC 2002 Hyperthermia-induced intestinal permeability and the role of oxidative and nitrosative stress. Journal of Applied Physiology 92 1750-1761. (doi:10.1152/japplphysiol.00787.2001)
Landman RE, Puder JJ, Xiao E, Freda PU, Ferin M \& Wardlaw SL 2003 Endotoxin stimulates leptin in the human and nonhuman primate. Journal of Clinical Endocrinology and Metabolism 88 1285-1291. (doi:10.1210/jc.2002-021393)

Lee IS, Shin G \& Choue R 2010 A 12-week regimen of caloric restriction improves levels of adipokines and pro-inflammatory cytokines in Korean women with BMIs greater than $23 \mathrm{~kg} / \mathrm{m}^{2}$. Inflammation Research 59 399-405. (doi:10.1007/s00011-009-0113-8)

Lindquist S 1986 The heat-shock response. Annual Review of Biochemistry 55 1151-1191. (doi:10.1146/annurev.bi.55.070186.005443)

del Mar Romero M, Fernández-López JA, Esteve M \& Alemany M 2009 Different modulation by dietary restriction of adipokine expression in white adipose tissue sites in the rat. Cardiovascular Diabetology 8 42-55. (doi:10.1186/1475-2840-8-42)

Nogueiras R, Tovar S, Mitchell SE, Rayner DV, Archer ZA, Dieguez C \& Williams LM 2004 Regulation of growth hormone secretagogue receptor gene expression in the arcuate nuclei of the rat by leptin and ghrelin. Diabetes 53 2552-2558. (doi:10.2337/diabetes.53.10.2552)

O'Brien MD, Rhoads RP, Sanders SR, Duff GC \& Baumgard LH 2010 Metabolic adaptations to heat stress in growing cattle. Domestic Animal Endocrinology 38 86-94. (doi:10.1016/j.domaniend.2009.08.005)

Park HG, Han SI, Oh SY \& Kang HS 2005 Cellular responses to mild heat stress. Cellular and Molecular Life Sciences 62 10-23. (doi:10.1007/s00018-004-4208-7)

Rabe K, Lehrke M, Parhofer KG \& Broedl UC 2008 Adipokines and insulin resistance. Molecular Medicine 14 741-751. (doi:10.2119/ 2008-00058.Rabe)

Renaudeau D, Noblet J \& Dourmad JY 2003 Effect of ambient temperature on mammary gland metabolism in lactating sows. Journal of Animal Science 81 217-231.

Ritchie KP, Keller BM, Swed KM \& Lepock JR 1994 Hyperthermia (heat shock) induced protein denaturation in liver, muscle and lens tissue as determined by differential scanning calorimetry. International Journal of Hyperthermia 10 605-618. (doi:10.3109/ 02656739409022441)

Ronchi B, Bernabucci U, Lacetera N, Verini Supplizi A \& Nardone A 1999 Distinct and common effects of heat stress and restricted feeding on metabolic status of Holstein heifers. Zootecnica e Nutrizione Animale 25 11-20.

Sano H, Takahashi K, Ambo K \& Tsuda T 1983 Turnover and oxidation rates of blood glucose and heat production in sheep exposed to heat. Journal of Dairy Science 66 856-861. (doi:10.3168/jds.S00220302(83)81867-0)

Sharma HS 2007 Methods to produce hyperthermia-induced brain dysfunction. Progress in Brain Research 162 173-199. (doi:10.1016/ S0079-6123(06) 62010-4)

Sinclair DA 2005 Toward a unified theory of caloric restriction and longevity regulation. Mechanisms of Ageing and Development 126 987-1002. (doi:10.1016/j.mad.2005.03.019)

Speakman JR \& Król E 2010 Maximal heat dissipation capacity and hyperthermia risk: neglected key factors in the ecology of endotherms. Journal of Animal Ecology 79 726-746. (doi:10.1111/ j.1365-2656.2010.01689.x)

Torlinska T, Banach R, Paluszak J \& Gryczka-Dziadecka A 1987 Hyperthermia effect on lipolytic processes in rat blood and adipose tissue. Acta Physiologica Polonica 38 361-366.

Wheelock JB, Rhoads RP, VanBaale MJ, Sanders SR \& Baumgard LH 2010 Effects of heat stress on energetic metabolism in lactating Holstein cows. Journal of Dairy Science 93 644-655. (doi:10.3168/jds. 2009-2295)

Zhang HJ, Drake VJ, Morrison JP, Oberley LW \& Kregel KC 2002 Selected contribution: differential expression of stress-related genes with aging and hyperthermia. Journal of Applied Physiology 92 1762-1769.

Received in final form 10 January 2012

Accepted 25 January 2012

Made available online as an Accepted Preprint 25 January 2012 